\title{
Study on the Varying Patterns of Total Phospholipids, Selenium, Phosphorus, Reducing Sugar and Total Sugar, Hydrolyzed Amino Acids in the Velvet Antler of Northeast Sika Deer in Growth Period
}

\author{
Shu-li Wang ${ }^{1}$, Yan-mei Wang ${ }^{1}$,a \\ ${ }^{1}$ Ginseng and Antler Products Testing Center of the Ministry of Agriculture PRC, Jilin Agriculture University, Changchun 130118, China
}

\begin{abstract}
In this study, the varying patterns of total phospholipids, selenium, phosphorus, reducing sugar and total sugar, hydrolyzed amino acids in the velvet antler of Northeast sika deer in growth period were evaluated. Eighteen Northeast sika deer were allocated into 6 groups according to the antler shedding time. Results indicated that there was significant difference of the selenium content between any two of the six groups $(\mathrm{P}<0.05)$ except that of Group 1 and Group 2 or Group 5 and Group 6. About the phosphorus there was significant difference between any two of the six groups $(\mathrm{P}<0.05)$ except that of Group 4 and Group 5 or Group 2 and Group 3 or Group 1 and Group 2. Group 6 had the lowest total Phospholipids content. Both of the reducing sugar and total sugar showed an increasing pattern initially and then decrease gradually.
\end{abstract}

\section{Introduction}

The velvet antler is the non-ossification horn of cervidae animals such as Northeast sika deer and red deer. It is a famous traditional Chinese medicine that owns many beneficial effects. Therefore, velvet antler was wildly used in the folk medicine [1]. Velvet antler contains protein, amino acids, peptide, trace elements, phospholipid, fatty acids, and so on [2]. In addition, it also contains some components like chondroitine, acidic polysaccharose, mucopolysaccharides [3, 4]. In this study, the varying patterns of total phospholipids, selenium, phosphorus, reducing sugar and total sugar, hydrolyzed amino acids in the velvet antler of Northeast sika deer in growth period were evaluated. And this may provide some theoretical foundations for the manufacture of velvet antler-health care products. $[5,6]$

\section{Experimental Section}

\subsection{Animals and sampling}

The velvet antlers were collected from the deer farm of Dongfeng Pharmaceutical factory. Eighteen Northeast sika deer with an average age of four years. Velvet antler with a length of $1 \mathrm{~cm}$ was sampled after the animals were anesthetized. The blood in the velvet antler was drained with the vacuum pump [7]. The velvet antler was dried with the vacuum freeze drier and the weight was recorded.

\subsection{Apparatus and methods}

In this study, AFS-933 atomic fluorescence spectrophotometer, DK20 Multi-function digestion device, and Beck-man DU-7500 ultraviolet spectrophotometer were employed. Selenium, phosphorus, total phospholipids, reducing sugar, and total sugar were analyzed according to the followings methods, respectively (Table 1).

Table 1. The content of selenium and phosphorus

\begin{tabular}{|l|l|}
\hline Items & Methods \\
\hline Selenium & GB 5009.93 \\
\hline Phosphorus & GB12393 \\
\hline Total phospholipids & Duan et al., 1988 [8] \\
\hline Reducing sugar & $\begin{array}{l}\text { NY 318 1997-Ginseng } \\
\text { products [9] }\end{array}$ \\
\hline Total sugar & Lou et al., 2003 [10] \\
\hline Hydrolyzed amino acids & GB/T5009.124 \\
\hline
\end{tabular}

\subsubsection{Selenium}

Accurately weigh a certain amount of sample Weigh $0.5 \mathrm{~g}$ $\sim 2 \mathrm{~g}$ sample, liquid sample lessons $1.00 \mathrm{~mL} \sim 10.00 \mathrm{~mL}$, placed in the digestion flask, add $10.0 \mathrm{~mL}$ mixed acid and a few grains of glass beads, covered with a watch glass of cold digestion overnight. The next day on a hot plate heated and timely additional nitric acid. When the solution becomes clear and colorless with white smoke, the heating was continued to a residual volume of about $2 \mathrm{~mL}$, must not be evaporated to dryness. Cooling, plus

\footnotetext{
a Corresponding author: yanmeimeiw@163.com
} 
5.0mL hydrochloric acid, and heating was continued until the solution becomes clear and colorless with white smoke appears, hexavalent selenium reduced to tetravalent selenium. Cooled and transferred to a $50 \mathrm{~mL}$ volumetric flask to volume and mix aside. While doing the blank test.

Instrument Reference conditions: negative high voltage: $340 \mathrm{~V}$; lamp current: $100 \mathrm{~m} \mathrm{~A}$; atomization temperature: $800{ }^{\circ} \mathrm{C}$; furnace height: $8 \mathrm{~mm}$; carrier gas flow rate: $500 \mathrm{~mL} / \mathrm{min}$; shielding gas flow rate: 1000 $\mathrm{mL} / \mathrm{min}$; measurement: standard curve method; reading mode: peak area; delay time: $1 \mathrm{~s}$; reading time: $15 \mathrm{~s}$; dosing time: $8 \mathrm{~s}$; injection volume: $2 \mathrm{~mL}$. setting the optimal conditions for the instrument, the furnace temperature was raised gradually to the desired temperature, start measuring stable after $10 \mathrm{~min} \sim 20 \mathrm{~min}$. Continuous series of zero standard tube injection until after the reading has stabilized, the standard series of measurements into the standard curve. Into the sample measurement, the sample and blank samples were measured digestive, before each test different samples should be cleaned injector.

\subsubsection{Phosphorus}

Accurately weigh a certain amount of sample Weigh $0.1 \sim$ $0.5 \mathrm{~g}$ in the $100 \mathrm{~m}$ L Kjeldahl flask, $3 \mathrm{~m}$ L sulfuric acid, $3 \mathrm{~m}$ $\mathrm{L}$ perchloric acid - nitric acid digestion, placed on digestion furnace, beginning to brown-black liquid bottle. When the solution turned to be colorless or slight yellow clear liquid that is completely digested. The solution was allowed to cool, after the transfer plus $20 \mathrm{~m} \mathrm{~L}$, cooled to $100 \mathrm{~m}$ L flask, washed several times with water Kjeldahl flask washings were combined into the volumetric flask, add water to volume, and mix. This solution is a liquid sample measurement. digested sample taken with the same amount of sulfuric acid, perchloric acid - nitric acid digestion, according to the same method blank solution. phosphorus standard curve Imbibe phosphorus.standard solution $0,0.5,1.0,2.0,3.0,4.0,5.0 \mathrm{~mL}$, were placed $20 \mathrm{~mL}$ stoppered test tube, followed by adding $2 \mathrm{~mL}$ molybdic acid solution shake and let stand a few seconds. Join $1 \mathrm{~m}$ L sodium sulfite solution, $1 \mathrm{~m}$ L hydroquinone solution shake. Add water to volume, and mix. Standing $0.5 \mathrm{~h}$ later absorbance was measured at $660 \mathrm{~nm}$ wavelength spectrophotometer. To measure the absorbance of the standard curve for phosphorus content.

Imbibe the measured liquid $2 \mathrm{~m}$ blank solution $\mathrm{L}$ and the same amount of samples were placed $20 \mathrm{~m} \mathrm{~L}$ stoppered test tube, and the remaining steps with the standard curve to measure the absorbance Richard unknown liquid phosphorus content standard curve.

\subsubsection{Total phospholipids}

Weigh $2 \mathrm{~g}$ sample in a stoppered Erlenmeyer flask, Folch reagent (chloroform - methanol 2: 1) $20 \mathrm{~m} \mathrm{~L}$, said that given the weight, ultrasound extraction $1 \mathrm{~h}$, placed at room temperature, weighed and the weight, plus Folch reagent re-fill, $3000 \mathrm{r} \cdot \min -1$, centrifugal $5 \mathrm{~min}$, the supernatant was filtered to $25 \mathrm{~m} \mathrm{~L}$ flask, with Folch reagent to the mark, as the test solution.

\subsubsection{Reducing sugar}

Accurately weighed sample $2 \mathrm{~g}$, set in the $100 \mathrm{~mL}$ beaker, added 85 ring ethanol $50 \mathrm{~mL}$, mixing, holding $30 \mathrm{~min}$ at $500 \mathrm{C}$ in a water bath, filtered, and the residue was then $85 \%$ ethanol solution was extracted twice, and the filtrate were combined, the ethanol was evaporated, add a small amount of distilled water and a total volume of $100 \mathrm{~mL}$.

After each tube and mix prepared standard curve method of operating a measured absorbance of each tube, to identify the appropriate reducing sugar content in the standard curve, the samples reducing sugar.

\subsubsection{Total sugar}

Weigh $1 \mathrm{~g}$ sample in a test tube, added $10 \mathrm{~mL}, 15 \mathrm{~mL}$ hydrochloric acid solution and distilled water mixed and heated for $30 \mathrm{~min}$, a solution of iodine with potassium iodide to check the degree of hydrolysis in a boiling water bath, if it has completely hydrolyzed, was not blue color (of starch), cooled I added drops of phenolphthalein indicator, with a $10 \%$ sodium hydroxide solution to reddish, filtered and set the volume to $100 \mathrm{~mL}$. And then to learn the exact solution $10 \mathrm{ml}$, set people $100 \mathrm{~mL}$ volumetric flask with distilled water to the mark.

After each tube and mix prepared standard curve method of operating a measured absorbance of each tube, to identify the appropriate reducing sugar content in a standard curve of the samples to the total sugar content.

\subsubsection{Hydrolyzed amino acids}

Accurately weigh a certain amount of sample to the nearest $0.0001 \mathrm{~g}$, sample weight within 10 20 mg, saying that a good sample put in the hydrolysis tube. Hydrolysis: Add in the hydrolysis tube $6.0 \mathrm{~mol} / \mathrm{L} \mathrm{HCl} 15.00 \mathrm{~mL}$, was added thioglycolic acid $1.00 \mathrm{ml}$ (for protection), cover stopper with vacuum pump to vacuum, tap into 0 psi, this hydrolysis tube and placed in the oven thermostat seal $110^{\circ} \mathrm{C} \pm 1{ }^{\circ} \mathrm{C}$ after $24 \mathrm{~h}$ of incubation, remove the cooling. Open hydrolysis tube stopper, the hydrolyzate was filtered and washed constant volume to $50.00 \mathrm{ml}$ volumetric flask. $1.00 \mathrm{ml}$ draw in the filtrate was $25 \mathrm{ml}$ beaker, evaporated to dryness on a water bath, the residue was dissolved in water $1 \sim 2 \mathrm{ml}$, then dried up again evaporated to dryness three times, and finally the residue was $0.02 \mathrm{~mol} / \mathrm{L} \quad \mathrm{HCl} \quad 1.00 \mathrm{~mL}$ dissolved machine measurement.

\section{Results and Analysis}

\subsection{The contents of selenium and phosphorus in the velvet antler}

Results indicated that there was significant difference of the selenium between any two of the six groups $(\mathrm{P}<0.05)$ except that of Group 1 and Group 2 or Group 5 and 
Group 6. About the content of phosphorus there was significant difference between any two of the six groups $(\mathrm{P}<0.05)$ except that of Group 4 and Group 5 or Group 2 and Group 3 or Group 1 and Group 2 (Table 2).

Table 2. The contents of selenium and phosphorus in the velvet antler

\begin{tabular}{|l|l|l|}
\hline Group & Selenium (ng/g) & Phosphorus (\%) \\
\hline 1 & $211.41 \mathrm{a}$ & $5.05 \mathrm{~d}$ \\
\hline 2 & $221.34 \mathrm{a}$ & $5.86 \mathrm{~cd}$ \\
\hline 3 & $186.24 \mathrm{~b}$ & $6.57 \mathrm{c}$ \\
\hline 4 & $150.44 \mathrm{c}$ & $7.5 \mathrm{~b}$ \\
\hline 5 & $124.01 \mathrm{~d}$ & $7.86 \mathrm{~b}$ \\
\hline 6 & $131.31 \mathrm{~cd}$ & $8.81 \mathrm{a}$ \\
\hline
\end{tabular}

Selenium is an important ingredient of glutathione peroxidase and many health care products were wildly consumed because of their high content of this element. As we known, velvet antler was rich in selenium too. Results in this study indicated the highest content of selenium was at the 40 days after the antler shedding. Phosphorus is vital to the life because it is not only the ingredient of nucleic acid and ATP, but also makes up a lot of enzymes with the other elements. Such results Antler Growth Law emergence are inseparable. Deer stag in mid-April after a year in late fall to early May faceplate, antler began to rapidly grow, reached a peak of about 70 $\mathrm{d}$, before the peak of the growth, the growth rate is greater than the speed of ossification, ossification and then faster than the growth rate, and then dried skin off bone horn, bones, horns last fall, the end of an antler growth cycle. Velvet deposited nutrients in addition to the outer part of the minerals by food intake, and thus this body needs to absorb a large number of deer nutrients for the growth of the supply of velvet. Phosphorus involved in energy metabolism, the body if the lack of Phosphorus, the bone marrow, tooth development is not normal. Osteoporosis, softening, easy to fracture or suffer from rickets in children, loss of appetite, muscle weakness.

The content of phosphorus was increased as the shedding time of velvet antler prolonged. Phospholipids can not only facilitate the cell renewal and maintain the metabolism, but also promote the immunity and regenerative capacity of human beings $[11,12]$.

\subsection{The contents of total phospholipids, reducing sugar and total sugar in the velvet antler}

Table 3. The contents of total phospholipids, reducing sugar and total sugar in the velvet antler

\begin{tabular}{|l|l|l|l|}
\hline Groups & $\begin{array}{l}\text { Total } \\
\text { phospholipids (\%) }\end{array}$ & $\begin{array}{l}\text { Reducing } \\
\text { sugar (\%) }\end{array}$ & $\begin{array}{l}\text { Total } \\
\text { sugar (\%) }\end{array}$ \\
\hline 1 & $2.45 \mathrm{ab}$ & $0.24 \mathrm{~d}$ & $3.61 \mathrm{e}$ \\
\hline 2 & $2.39 \mathrm{ab}$ & $0.39 \mathrm{c}$ & $4.42 \mathrm{~d}$ \\
\hline 3 & $2.54 \mathrm{a}$ & $0.54 \mathrm{a}$ & $5.04 \mathrm{c}$ \\
\hline 4 & $2.62 \mathrm{a}$ & $0.50 \mathrm{ab}$ & $6.15 \mathrm{a}$ \\
\hline 5 & $2.67 \mathrm{a}$ & $0.47 \mathrm{~b}$ & $5.61 \mathrm{~b}$ \\
\hline 6 & $2.18 \mathrm{~b}$ & $0.32 \mathrm{c}$ & $5.73 \mathrm{ab}$ \\
\hline
\end{tabular}

Generally, Group 5 had the highest total phospholipids content $(\mathrm{P}<0.05)$ whereas Group 6 had the lowest $(\mathrm{P}<0.05)$.
The sugar is an important organic compound which is widely distributed in the natural world. It is one of the primary sources for life sustaining. Both of the reducing sugar and total sugar showed an increasing pattern initially and then decrease gradually (Table 3).

The experiment measured plum velvet herbs total phospholipid content, slightly lower than the reported in the literature, may be related to Antler taken herbs processing methods; about Deer Antler total phospholipid content has not been reported. Determination of the total phospholipid content of common mainly colorimetry and HPLC. Phospholipid assay is converted to inorganic phosphorus colorimetrically to calculate the total phosphorus content of the phospholipid content. The HPLC method is generally measured total phospholipid content of each phospholipid component, summing the total phospholipid content of each phospholipid content, this method has the instrument detects a bit fast, but many phospholipid components, each group is not easy to points are measured completely [13], and the price is relatively expensive Ao, measured in terms of total phospholipid higher costs. The colorimetric test solution by a standard phosphorus as a low cost reference and measurement method is simple, the application is also more practical significance to promote [14].

Antler is a valuable traditional Chinese medicine, complex composition, in recent decades, and found a variety of active ingredients, such as amino acids, fatty acids, chondroitin sulfate, hypoxanthine, uracil, and phospholipids polyamine compounds [15]. Wherein the phospholipid is considered to be one of the active ingredients [16], in addition to inhibition of monoamine oxidase activity action outside, stimulate growth and hematopoietic function, enhance the regeneration process and improved neuromuscular function of the system antler etc, velvet phospholipids effect is closely related to. Antler existing literature on total phospholipid segmented detection, content decreasing from top to bottom [17], but did not find them in the diversity of the statistical analysis report.

\subsection{Results of hydrolyzed amino acids}

Table 4 The content of hydrolyzed amino acids

\begin{tabular}{|l|l|l|}
\hline Group & $\begin{array}{l}\text { Amino acid at the } \\
\text { middle of velvet } \\
\text { antler (\%) }\end{array}$ & $\begin{array}{l}\text { Amino acid at the } \\
\text { top of velvet antler } \\
(\%)\end{array}$ \\
\hline 1 & $47.55 \mathrm{a}$ & $57.15 \mathrm{ab}$ \\
\hline 2 & $45.35 \mathrm{ab}$ & $59.62 \mathrm{a}$ \\
\hline 3 & $40.25 \mathrm{c}$ & $50.86 \mathrm{c}$ \\
\hline 4 & $40.13 \mathrm{c}$ & $50.67 \mathrm{c}$ \\
\hline 5 & $39.05 \mathrm{c}$ & $51.78 \mathrm{bc}$ \\
\hline 6 & $41.35 \mathrm{bc}$ & $62.95 \mathrm{a}$ \\
\hline
\end{tabular}

Note: the different superscripts of the data on the same row means significant difference $(\mathrm{P}<0.05$ or $\mathrm{P}<0.01)$

It can be indicated from this Table 4 that among the hydrolyzed amino acids of velvet antler of Northeast Sika Deer in different growth periods, there are significant difference of amino acids content at the middle of velvet antler between group 1 and 3, 4, 5, $6(\mathrm{p}<0.05)$, and 
between group 2 and 3, 4, 5, $6(\mathrm{p}<0.05)$. There are significant difference of amino acids content at the top of velvet antler between group 1 and $3,4,6$, between group 2 and 3, 4, 5, and between group 6 and 3, 4, $5(\mathrm{p}<0.05)$.

Amino acids are organic component velvet topped the content of nutrients, the highest glycine; amino acids are the basic components of living organism tissue cells for life events play a pivotal role. If the body lacks any kind of essential amino acids, it can cause physiological dysfunction, affecting the normal antibody metabolism [18], leading to disease. Similarly, if the body lacks certain non-essential amino acids, it will produce antibodies metabolic disorders. Arginine and citrulline formation of urea is very important; cystine intake will cause reduction of insulin, blood sugar. Another example is the post-traumatic cystine and arginine requirements increase [19], such as the lack of adequate energy even if you still can not synthesize proteins. Thus, the presence of amino acids in the human body, not only provides an important raw material for the synthesis of proteins, but also for the promotion of growth and normal metabolism, provides the material basis of life-sustaining

\section{Conclusions}

Selenium is an important ingredient of glutathione peroxidase and many health care products were wildly consumed because of their high content of this element. As we known, velvet antler was rich in selenium too. Results in this study indicated the highest content of selenium was at the 40 days after the antler shedding. Phosphorus is vital to the life because it is not only the ingredient of nucleic acid and ATP, but also makes up a lot of enzymes with the other elements. The content of phosphorus was increased as the shedding time of velvet antler prolonged. Phospholipids can not only facilitate the cell renewal and maintain the metabolism, but also promote the immunity and regenerative capacity of human beings [20]. Generally, Group 5 had the highest total phospholipids content $(\mathrm{P}<0.05)$ whereas Group 6 had the lowest $(\mathrm{P}<0.05)$. The sugar is an important organic compound which is widely distributed in the natural world. It is one of the primary sources for life sustaining [21]. Both of the reducing sugar and total sugar showed an increasing pattern initially and then decrease gradually. These data may provide some theoretical foundations for the manufacture of velvet antler-health care products.

Amino acid is the basic unit composing the protein. Some physiological activities in velvet antler are directly correlated to the amino acid. The amino acid in human body provides the important material for protein synthesis, but also provides the material basis for promoting growth, normal metabolism and maintaining the life [22]. The content of hydrolyzed amino acids increases along with time, while the change is not regular but some groups of hydrolyzed amino acids show significant difference $(\mathrm{p}<$ 0.05 ), which may be correlated to the accumulation of amino acids at different time. All the results provide the scientific basis for collection and utilizaiton of velvet antler.

\section{Summary}

These data may provide some theoretical foundations for the manufacture of velvet antler-health care products.

\section{References}

1. The pharmacopoeia committee of China. China Pharmacopeia. (People's Medical Publishing House, China 2000).

2. B. Y. Wang and Q L. Zhou: Acta Pharmaceutica Sinica Vol. 26 (1991), p. 714-720.

3. F. Y. Dong, H, Zhang and Y. Chen: Jilin Journal of Traditional Chinese Medicine Vol. 18 (1998), p.62.

4. Wang Quanwei,Dong ZhenWang,Guiwu. Research Progress on Proteins Related to Deer Antler Regeneration, [J] Biotechnology Bulletin, 2015, $1.31 .8(24-29)$.

5. Zha Enhui, Li Xing xia, Li Dandan, et al.Immunomodulatory ef-fects of a $3.2 \mathrm{k}$ Da polypeptide from velvet antler of Cervus nip-pon Temm inck [ J] .International Immunopharm acology, 2013, $16: 210-213$

6. Sui Zhigang, Zhang Lihua, Huo Yushu, et al .Bioactive componentsof velvet antlers and their pharm acological properties[J]. Journalof Pharm aceutical and Biomedical Analysis, 2013(8):1-12.

7. Farberov S, Meidan R. Functions and transcriptional regulation of thrombospondins and their interrelationship with fibroblast growth factor-2 in bovine luteal cells [J]. Biol Reprod, 2014, 91 (3): 58.

8. C. F. Duan, X. H. Gao and J. H. Wang: Special Wild Economic Animal and Plant Research Vol. 4 (1988), p. 41-43.

9. NY318 1997-Ginseng products. (China Standards Press, China 1998).

10. X. H. Lou and Q. F. Wu: China Pharmaceuticals Vol. 12 (2003), p. 57.

11. M. Sadighi, S.R. Haines A. SkottnerA.J. Harris and J.M. Suttie: Journal of Endocrinology Vol. 143 (1994), p. 461-469.

12. R.R. Dalefield and F.W. Oehme: Veterinary and human toxicology Vol. 41 (1999), p. 39-41.

13. John Mikler,Christine Theoret,Jerry C.Effects of Topical Elk Velvet Antler on Cutaneous Wound Healing in Strepto-zotocin-Induced Diabetic Rats High. Alternative and Complementary Medicine. 2004

14. L Eriksson, E Johansson, N Kettaneh-Wold, J Trygg, C Wikstrom, S Wold.Multi- and megavariate data analysis part I: basic principles and applications, second revised and enlarged edition. 2006

15. M. G. Horning, K. L. Knox,C. E. Dalgliesh,E. C. Horning.Gas-liquidchromato-graphic study and estimation of several urinary aromatic acids. Analytical Biochemistry. 1966

16. N. Boussetta, E. Vorobiev, L. H. Le, A. Cordin-Falcimaigne, J.-L. Lanoisellé. Application of electrical treatments in alcoholic solvent for polyphenols extraction from grape seeds [J]. LWT Food Science and Technology. 2011 (1) 
17. Zhou Q L, Guo Y J, Wang L J, et al. Velvet antler polypeptides promoted proliferation of chondrocytes and osteoblast precursors and fracture healing. Acta Pharmacological Sinica. 1999

18. R L Garcia, M Sadighi, S M Francis, J M Suttie, J S Fleming.Expression of neurotrophin-3 in the growing velvet antler of the red deer Cervus elaphus. Journal of Molecular Endocrinology . 1997

19. C. Li, J. M. Suttie. Deer antlerogenic periosteum: a piece of postnatally retained embryonic tissue? [J]. Anatomy and Embryology. 2001 (5)
20. J. F. Wang, D. C. Li and Z. Li: Biochemistry. (Chinese Press of Traditional Chinese Medicine, China 2002.

21. Pei Wenxuan, Li, Fei, Dong Ling, Review of Chemical Components and Biological Effect of Pilose Antler, $[\mathrm{J}]$ World Science and Technology/Modernization of Traditional Chinese Medicine and Materia Medica, 2012,05:2065-2069.

22. Hong $\mathrm{H}$, Zhou $\mathrm{T}$, Fang $\mathrm{S}$, et al. Pigment epithelium-derived factor ( PEDF) inhibits breast cancer metastasis by down-regulating fibronectin [J]. Breast Cancer Res Treat, 2014, 148 (1), 61-72. 